\title{
Knowledge of Integrated Pest Management (IPM) Practices among Chilli Farmers in Raichur District of Karnataka, India
}

\author{
S.M. Mahalakshmi ${ }^{1 *}$ and J. Tulasiram ${ }^{2}$ \\ ${ }^{1}$ Department of Agricultural Extension, UAS, GKVK, Bengaluru-560065, Karnataka, India \\ ${ }^{2}$ Department of Agricultural Extension Education, UAS, Raichur, India \\ *Corresponding author
}

\section{A B S T R A C T}

The present study was undertaken during the year 2015-16 in the selected two taluks of Raichur district of Karnataka state. Based on maximum area under chilli cultivation, two

\section{Keywords}

Intercultivation, Integrated pest management,

Knowledge and NSKE

Article Info

Accepted:

20 February 2018

Available Online:

10 March 2018 talukas were selected. From each taluka, three villages were selected based on maximum number of chilli growing farmers. From each village, 20 chilli growing farmers were selected thus constitute a sample size of 120 for the study. The data was collected from the respondents using structured interview schedule developed for the purpose. The data collected was analyzed and tabulated using appropriate statistical tools. The results of the study revealed that, majority of the chilli farmers possessed high $(40.00 \%)$ level of knowledge about integrated pest management practices. Cent per cent of chilli farmers have knowledge about summer ploughing, removal of previous crop residues, application of FYM, trimming of field bunds, intercultivation followed by benefits of summer ploughing $(98.33 \%)$, practice of crop rotation $(96.67 \%)$ and raised nursery bed $(80.00$ $\%)$. Cent percent of farmers possessed knowledge about regular destruction of damaged fruits at each harvest. Around sixty per cent of respondents $(62.50 \%)$ had knowledge about use of neem seed kernel extract. Cent per cent of the farmers had knowledge about control of fruit borers, thrips and mites.

\section{Introduction}

India ranks second in the cultivation of vegetables in the world. Vegetables being rich in minerals and nutrition value are being grown in almost all the states in the country under varied agro-climatic and soil conditions in plains as well as hilly regions.

Chilli (Capsicum annuum Linn) is one of the important spice/vegetable/cash crops grown in India and known as the 'King of Spices', it belongs to genus Capsicum under Solanaceae family. It is also called as red pepper, an important condiment crop, grown for its pungent fruits which are used both as green and riped to impart pungency to food. It is an indispensable spice crop used in every Indian cuisine due to its color, pungency, taste, appealing odours and flavor. Chilli fruits are rich source of vitamin $\mathrm{A}, \mathrm{C}$ and $\mathrm{E}$.

In the world, chilli is cultivated in an area of 1.45 million hectares with an annual 
production of 19.50 million tonnes and productivity of $2,808 \mathrm{~kg} / \mathrm{ha}$ (Anon., 2013). The top 10 chilli producing countries are India, China, Ethiopia, Myanmar, Mexico, Vietnam, Peru and Pakistan. India accounted for more than 85 per cent of the world production in 2012 (www.faostat.in). In India, chilli is grown in almost all states of the country. The important states growing chilli in terms of production are Andhra Pradesh (60 \%) followed by Karnataka (11\%), west Bengal (7 \%), Orissa (5\%), Madhya Pradesh (3\%), Maharashtra (3\%) and Tamil Nadu $(2.6 \%)$.

In Karnataka, chilli is grown in an area of 100.73 thousand hectares with a production of 107.00 thousand MT and productivity of 1.06 MT/ha in 2011-12 to 2013-14. (Source: Ministry of Agriculture, Govt. of India). Various extension programmes were being implemented by Government of Karnataka with the intention of popularizing IPM technology and at present very few research studies have been conducted to support the impact of programmes interns of extent of knowledge and adoption of IPM practices among vegetable growers, economic benefits and constraints being faced in complete adoption of IPM method in vegetables. Several studies have been conducted on food crops to know the knowledge and adoption, but very few research studies have been conducted on spice crops in this regard. With this background, the present study was undertaken with an objective to know the extent of knowledge possessed by the chilli growers in integrated pest management practices.

\section{Materials and Methods}

The present study was conducted in Raichur district of Karnataka during the year 2015-16. Raichur district was purposively selected for the study because of convenience and familiarity of the researcher with the study area. Among the spice crops, chilli is one of the major crops grown by the farmers in the district. Among the five taluks of the Raichur district, Raichur and Devadurga taluks were selected based on the highest area under cultivation of chilli. On the basis of maximum number of chilli growing farmers in each taluk three villages were selected randomly thus making 6 villages from 2 taluks.

From each of the selected village, 20 chilli growing farmers were selected using simple random sampling technique. Thus the total sample constituted 120 chilli farmers for the study. The data was collected from the respondents using structured interview schedule develop for the study. The data collected was analyzed and tabulated using appropriate statistical tools.

\section{Results and Discussion}

\section{Overall knowledge of IPM practices in chilli}

The results presented in Table 1 revealed that, more than one third $(40.00 \%)$ of respondents belonged to high knowledge category, followed by medium (32.50 \%) and low $(27.50 \%)$ knowledge categories with respect to IPM practices in chilli.

This clearly shows that the respondents had high level of knowledge, which might be due to the fact that, majority of the respondents, had high extension participation, risk orientation and farming experience. Above all majority of respondents belongs to middle age category and middle aged farmers who are more enthusiastic and to know innovations than others.

Similar results were also reported by Patel and Sanwal (2015). 
Extent of knowledge level of individual IPM practices in chilli crop

The data pertaining to extent of knowledge of individual integrated pest management practices by chilli growers is presented in Table 2.

With respect to cultural practices, cent per cent of respondents had knowledge about removal of previous crop residues, practice of summer ploughing, application of FYM, trimming of field bunds and intercultivation, followed by benefits of summer ploughing $(98.33 \%)$, crop rotation $(96.67 \%)$, benefits of trimming bunds $(95.83 \%)$, advantages of crop rotation $(94.17 \%)$. Major portion of respondents had knowledge about practice of raised bed and growing of trap crops, followed by use of recommended seed rate $(61.67 \%)$. Removal of crop residues, summer ploughing, application of FYM, intercultivation etc are the age old practices followed by farmers since many years and due to which majority of them will have knowledge regarding those practices.

With regard to mechanical control measures, cent per cent of the respondents had knowledge about regular destruction of damaged fruits at each harvest stage followed by advantages of regular destruction of damaged fruits $(97.50 \%)$, regular destruction of infected flowers of trap crop (80.00\%), use of pheromone traps $(65.00 \%)$, use of mesh nylon net $(45.83 \%)$ and advantages of using nylon net $(42.50 \%)$.

Awareness of chilli farmers regarding importance of these practices in IPM and participation of farmers in extension activities might be the probable reasons for above findings.

In case of biological management measures, 69.17 per cent of respondents had knowledge about growing pulses on the bunds to build up natural enemies followed by use of NSKE $(62.50 \%)$, benefits of neem extracts $(60.83$ $\%$, application of NPV and Pseudomonas $(56.67 \%)$, seed treatment with biofertilizer (45.83\%), spraying of NSKE on trap crop $(42.50 \%)$, stage of pest controlled by NPV (37.50\%), quantity of Pseudomonas to be applied $(31.67 \%)$. Whereas, quantity of NSKE to be applied and time of spraying NPV was known to 22.50 and 17.5 per cent of the respondents respectively.

This shows that farmers were very much lacking the knowledge about NPV application. Lack of conviction, nonavailability of NPV, lack of technical knowledge, practical application and guidance about use of NPV, complexity of the practice and fear of decline in the yield might be the probable reasons for lack of knowledge about use of NPV and pseudomonas among the respondents.

Kiruthika (2013) reported that, nearly 25 percent of the onion growers were aware of the important IPM practice Trichoderma viride followed by Pseudomonas fluorescens $(22.35 \%)$, yellow sticky trap (3.03\%) and Vesicular Arbuscular Mycorrhiza (3.03\%). Nearly one fourth of them aware of neem products. None of them were aware of pheromone traps.

With respect to chemical management measures, cent per cent of the respondents had knowledge regarding fruit borers, thrips and mites management followed by use of recommended dose of pesticides $(95.83 \%)$ and seed treatment with chemical and aphids control $(93.33 \%)$. Use of balanced dose of fertilizers was known by 81.67 per cent of the respondents.

This shows that farmers were possessing better knowledge about control of insect pest 
than disease using chemical management measures. Regular consultation of input agencies, RSK officials for obtaining information, medium extension participation and mass media participation might be the probable reasons for above findings.

It is logical to derive from the above discussion that, the practices which are complex and difficult to remember are moderately known to farmers on the other hand the practices which are simple and being practiced by forefathers are known to maximum extent of the farmers.

Singh and Narain (2014) also reported that, FYM/ brown manure with rank-I, followed by summer, deep ploughing, regular destruction of damaged fruit at each harvest, crop rotation and collection and destruction of larvae.

Relationship between socio-economic characteristics of respondents with knowledge of IPM practices

A cursory look at Table 3 showed that, variables like annual income, land holding and information seeking behaviour exhibited positive and significant relationship with knowledge level at 1 per cent level of probability. Whereas, management orientation exhibited positive and significant relationship with knowledge level of respondents at 5 per cent level of probability. This might be due to the fact that, farmers consult various sources for obtaining information regarding crop cultivation practices which intern enhances the knowledge.

Table.1 Distribution of chilli farmers based on their overall knowledge of IPM practices in chilli

\begin{tabular}{|r|lr|c|c|}
\hline \multirow{2}{*}{ Sl. no. } & \multicolumn{2}{|c|}{ Knowledge level } & \multicolumn{2}{c|}{ Number of respondents } \\
\cline { 3 - 5 } & & Frequency & Percent \\
\hline $\mathbf{1}$ & Low (Mean-0.425*SD) & 33 & 27.50 \\
\hline $\mathbf{2}$ & Medium $($ Mean $\pm 0.425 *$ SD) & 39 & 32.50 \\
\hline $\mathbf{3}$ & High (Mean $+0.425 *$ SD) & & 48 & 40.00 \\
\hline & & Mean & 25.48 \\
\hline
\end{tabular}

Table.2 Extent of knowledge level of individual IPM practices in chilli crop

$\mathrm{n}=120$

\begin{tabular}{|c|l|c|c|}
\hline $\begin{array}{c}\text { Sl. } \\
\text { no. }\end{array}$ & \multicolumn{1}{|c|}{ Practices } & \multicolumn{2}{c|}{ Knowledge } \\
\cline { 3 - 4 } & & Frequency & Percent \\
\hline I. & Cultural practices & 120 & 100.00 \\
\hline $\mathbf{1}$ & Removal of previous crop residues & 120 & 100.00 \\
\hline $\mathbf{2}$ & Practice of summer ploughing & 118 & 98.33 \\
\hline $\mathbf{2 a}$ & Benefits of summer ploughing & 96 & 80.00 \\
\hline $\mathbf{3}$ & Practice of raised nursery bed & 74 & 61.67 \\
\hline $\mathbf{4}$ & Recommended seed rate & 120 & 100.00 \\
\hline $\mathbf{5}$ & FYM & & \\
\hline
\end{tabular}




\begin{tabular}{|c|c|c|c|}
\hline 6 & Trimming of field bunds & 120 & 100.00 \\
\hline $\mathbf{6 a}$ & Benefits of trimming bunds & 115 & 95.83 \\
\hline 7 & Trap crops & 96 & 80.00 \\
\hline 8 & Intercultivation & 120 & 100.00 \\
\hline 9 & Crop rotation & 116 & 96.67 \\
\hline 9a & Advantages of crop rotation & 113 & 94.17 \\
\hline II. & \multicolumn{3}{|l|}{ Mechanical practices } \\
\hline 1 & Use of mesh nylon net & 55 & 45.83 \\
\hline 1a & Advantages of using nylon net & 51 & 42.50 \\
\hline 2 & Regular destruction of damaged fruits at each harvest & 120 & 100.00 \\
\hline $2 \mathbf{a}$ & Advantages & 117 & 97.50 \\
\hline 3 & Regular destruction of infected flowers of trap crop & 96 & 80.00 \\
\hline 4 & Use of Pheromone traps & 78 & 65.00 \\
\hline III. & \multicolumn{3}{|l|}{ Biological management } \\
\hline 1 & Use of NSKE & 75 & 62.50 \\
\hline 2 & NSKE on trap crop & 51 & 42.50 \\
\hline $2 \mathbf{a}$ & Quantity of NSKE & 27 & 22.50 \\
\hline 2b & Benefits of neem extracts & 73 & 60.83 \\
\hline 3 & Application of NPV and Pseudomonas & 68 & 56.67 \\
\hline 3a & Time of spraying NPV & 21 & 17.50 \\
\hline $3 \mathbf{b}$ & Stage of pest controlled by NPV & 45 & 37.50 \\
\hline 3c & Quantity of NPV and Pseudomonas & 38 & 31.67 \\
\hline 4 & Seed treatment with biofertilizer & 55 & 45.83 \\
\hline 5 & Growing pulses on the bunds to build up natural enemies & 83 & 69.17 \\
\hline IV. & \multicolumn{3}{|l|}{ Chemical management } \\
\hline 1 & Balanced dose of fertilizer & 98 & 81.67 \\
\hline 2 & Recommended dose of pesticides & 115 & 95.83 \\
\hline \multirow[t]{2}{*}{3} & Seed treatment with chemical & 112 & 93.33 \\
\hline & Pests & & \\
\hline a. & Fruit borers & 120 & 100.00 \\
\hline b. & Thrips & 120 & 100.00 \\
\hline c. & Mites & 120 & 100.00 \\
\hline d. & Aphids & 112 & 93.33 \\
\hline
\end{tabular}


Table.3 Relationship between socio-economic characteristics of respondents with knowledge of IPM practices

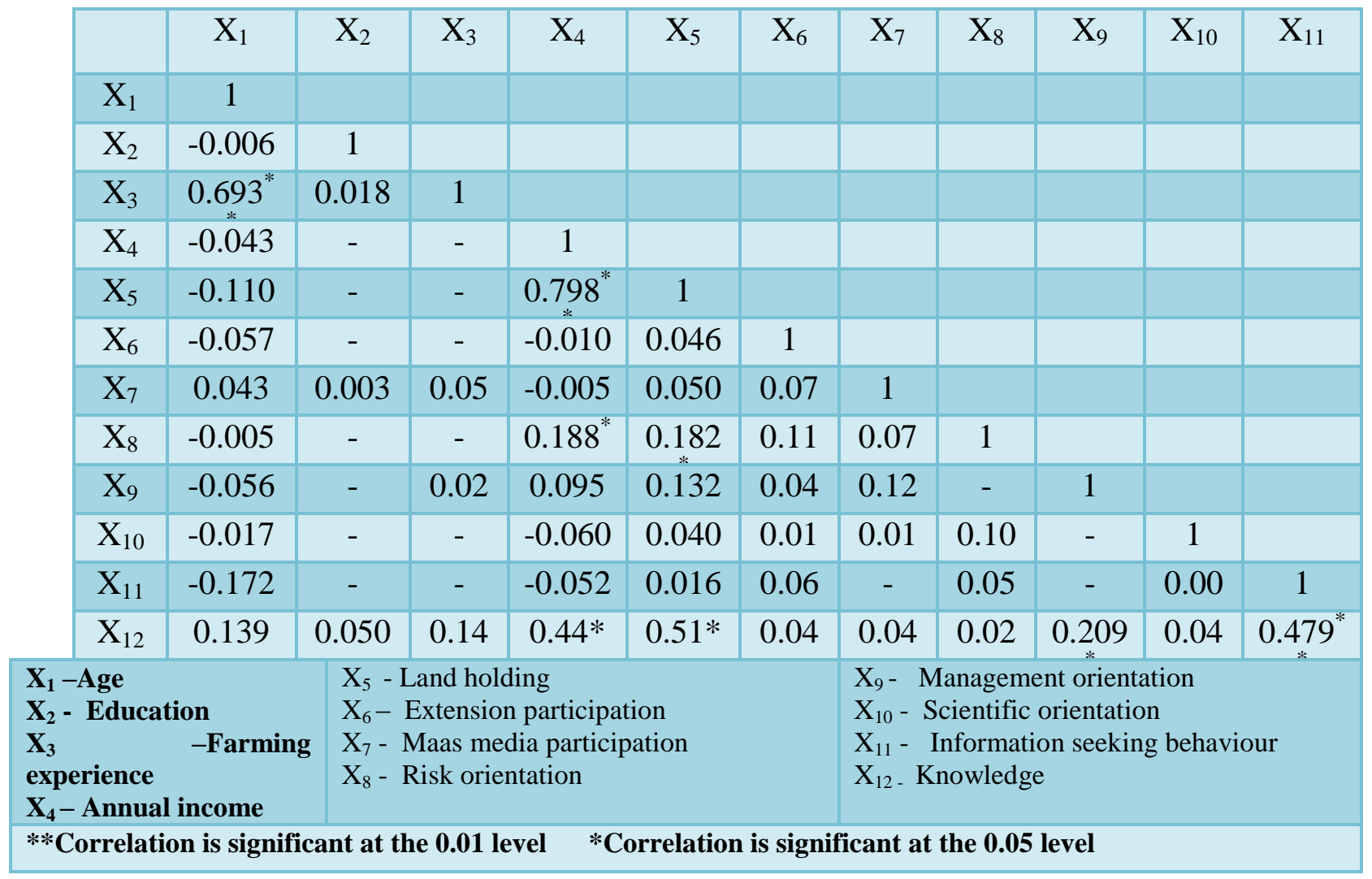

Table.4 Multiple regression analysis of characteristics of respondents and knowledge of IPM practices

\begin{tabular}{|c|l|c|c|}
\hline \multirow{2}{*}{ SL. no. } & \multicolumn{1}{|c|}{ Variables } & \multicolumn{2}{|c|}{ Knowledge } \\
\cline { 3 - 4 } & & Reg. Coeff. 'b' value & 't' value \\
\hline $\mathbf{1}$ & Age & 0.193 & 1.801 \\
\hline $\mathbf{2}$ & Education & 0.090 & 1.165 \\
\hline $\mathbf{3}$ & Farming experience & 0.075 & 0.695 \\
\hline $\mathbf{4}$ & Annual income & -0.233 & -1.775 \\
\hline $\mathbf{5}$ & Land holding & 0.119 & 0.913 \\
\hline $\mathbf{6}$ & Extension participation & 0.005 & 0.066 \\
\hline $\mathbf{7}$ & Maas media participation & 0.015 & 0.188 \\
\hline $\mathbf{8}$ & Risk orientation & 0.022 & 0.281 \\
\hline $\mathbf{9}$ & Management orientation & $0.232^{*}$ & 2.955 \\
\hline $\mathbf{1 0}$ & Scientific orientation & 0.054 & 0.686 \\
\hline $\mathbf{1 1}$ & Information seeking behaviour & $0.516^{* *}$ & 6.579 \\
\hline & & \multicolumn{2}{|c|}{$\mathrm{R}^{2}=0.467$} \\
\hline
\end{tabular}

** Significant at the 0.01 level $*$ Significant at the 0.05 level 
Multiple regression analysis of characteristics of respondents and knowledge of IPM practices

Multiple regression analysis was carried out for determining the contribution of independent variables with knowledge of IPM practices by the chilli farmers and the data, thus obtained, have been furnished in Table 4 .

Data presented in Table 4 revealed that, the variables like information seeking behaviour and management orientation had positively significant relationship with knowledge of respondents regarding IPM practices. Hence, these variables could be considered as good predictors of knowledge level of farmers regarding IPM practices in chilli crop. Whereas, co-efficient of determination $\left(\mathrm{R}^{2}\right)$ of the independent variables was 0.46 . It means that 46.70 per cent of total variation in the knowledge was explained by the 11 selected independent variables. It implied that there are other unidentified variables contributing to the variation not included in the present study.

It can be concluded from the results of the study that, majority of the chilli farmers belonged to high knowledge category with respect to IPM practices. High majority of them possessed correct knowledge regarding summer ploughing, removal of previous crop residues, application of FYM, trimming of field bunds, intercultivation followed by benefits of summer ploughing, practice of crop rotation, raised nursery bed, regular destruction of damaged fruits at each harvest, use of neem seed kernel extract and control of fruit borers, thrips and mites. Majority of the respondents still do not have complete knowledge about integrated pest management practices of chilli crop. Hence, it is imperative that the Developmental Departments, NGOs, State Agricultural universities and others to make integrated efforts in providing the recent techniques and knowledge about integrated pest management practices in chilli crop.

\section{References}

Anonymous, 2013, Spice Board of India.

Kiruthika, N., 2013, Adoption of integrated pest management (IPM) in vegetables: A case of onion in Tamil Nadu. American International Journal of Research in Humanities, Arts and Social Sciences, 2(2): 111-115.

Patel, R. M. and Sanwal, S., 2015, Knowledge of IPM Practices among Cotton Growers of Sabarkantha District; Gujarat, India. International Journal on Recent and Innovation Trends in Computing and Communication, 3(2): $444-446$.

Singh, S. and Narain, S., 2014, Knowledge and Adoption Level of IPM Practices among Tomato growers in Indore District (M.P.). Indian Res. J. Ext. Edu. 14 (3): 125-127.

www.faostat.in

\section{How to cite this article:}

Mahalakshmi, S.M. and Tulasiram, J. 2018. Knowledge of Integrated Pest Management (IPM) Practices among Chilli Farmers in Raichur District of Karnataka, India. Int.J.Curr.Microbiol.App.Sci. 7(03): 2196-2202. doi: https://doi.org/10.20546/ijcmas.2018.703.259 